\title{
Early and Late Functional Outcomes of Anal Sphincter- Sparing Procedures With Total Mesorectal Excision for Anorectal Adenocarcinoma
}

\author{
Osama Eldamshety ${ }^{1}$, Sherif Kotb ${ }^{1}$, Ashraf Khater ${ }^{1}$, Waleed Elnahas ${ }^{1}$, Sameh Roshdy ${ }^{1}$, Mohamed S. Zahi ${ }^{2}$, \\ Hend M.H. Rashed Elkalla ${ }^{2}$, Omar Farouk ${ }^{1}$, Ahmed Senbel ${ }^{1}$, Adel Fathi ${ }^{1}$, Emad-Eldeen Hamed ${ }^{1}$, \\ Khaled Abdelwahab ${ }^{1}$, Islam A. Elzahby ${ }^{1}$, Ahmed abdallah ${ }^{1}$, Mahmoud Abdelaziz $^{1}$, Emanuele Lezoche ${ }^{3}$ \\ ${ }^{1}$ Department of Surgery, Oncology Center of Mansoura University, Mansoura; ${ }^{2}$ Department of Clinical Oncology and Nuclear Medicine, \\ Mansoura University, Mansoura, Egypt; ${ }^{3}$ Department of Surgery Paride Stefanini, Policlinico Umberto Primo, SAPIENZA University of Rome, \\ Rome, Italy
}

Purpose: The study aims to assess the functional outcome of anal sphincter-sparing procedures (SSP) with total mesorectal excision (TME) for anorectal adenocarcinoma.

Methods: In a multicentric, prospective, single-group study in the period between December 2012 and November 2017, 93 patients presented with anorectal adenocarcinoma were included in the study. Sixty-nine patients underwent SSP with TME. SSP included the combined approach of transabdominal TME with intersphincteric resection (ISR) or transanal transabdominal TME. Using the per anal examination scoring system (PASS), postoperative anal function was assessed after 1 year.

Results: Bowel motility time was $50 \pm 19$ hours. The time needed for narcotic analgesia was $54 \pm 18.8$ hours. Mean hospital stay was $15.4 \pm 10.25$ days. Incidence of evident fecal incontinence after ISR is 10.6\% ( 7 of 67 cases). The PASS findings of 69 cases are as follows: extremely hypotonic $8.6 \%$ (6 cases), slightly hypotonic $26.1 \%$ (18 cases), normal tone $58 \%$ (40 cases), slightly stenotic 3 cases (4.3\%), or occluded $2.9 \%$ ( 2 cases). Urinary dysfunction occurred in 1 case (1.4\%). Temporary diversion was performed in 61 patients $(87.1 \%)$.

Conclusion: Sphincter preservation with TME for anorectal adenocarcinoma helps avoid permanent stoma and provides reasonable functional outcomes. PASS is a new application for postoperative assessment of anal function.

Keywords: Postoperative anal continence; Sphincter preservation; Total mesorectal excision; Anorectal adenocarcinoma; Very low rectal cancer

\section{INTRODUCTION}

In 1982, Heald et al. [1] introduced a surgical technique, total me-

Received: June 13,2018 - Accepted: July 19, 2018

Correspondence to: Osama Eldamshety, M.D.

Oncology Centre of Mansoura University, Rashad street, 4 int 5, Gharbya, Egypt

Tel: +201000178631 , Fax: +0402201188

E-mail:dr_osama_82@mans.edu.eg,dr_osama_82@yahoo.com

ORCID: https://orcid.org/0000-0002-9670-8753

(C) 2020 The Korean Society of Coloproctology

This is an open-access article distributed under the terms of the Creative Commons Attribution NonCommercial License (https://creativecommons.org/licenses/by-nc/4.0) which permits unrestricted non-

commercial use, distribution, and reproduction in any medium, provided the original work is properly cited. sorectal excision (TME), which has become the gold standard procedure for rectal cancer. Ideal surgery for rectal cancer should not only obtain adequate radial and circumferential margin (CRM), but also preserve normal sphincter function [2]. In 1990, the results of a 'close shave' on anterior resection were reported, suggesting that a resection margin of $1 \mathrm{~cm}$ or less produced an oncological outcome similar to that of a resection margin greater than $1 \mathrm{~cm}$ [3]. Research has been continued in an attempt to ensure good postoperative outcomes [4] and to study the oncological safety of ultralow anterior resection [5]. Despite the progress in the neoadjuvant therapy, radical resection of rectal carcinoma is the only hope for permanent cure of rectal cancer [6]. Continence-preserving radical resection and optimal local tumor con- 
trol are currently achievable goals in the treatment of ultralow rectal carcinoma. Successful excision of a low rectal tumor while preserving the anal sphincter requires knowledge of the pattern of tumor spread and an understanding of the physiology of the sphincter mechanism. The move towards sphincter-preserving surgery began with early anorectal physiology work demonstrating that the distal $1-2 \mathrm{~cm}$ of the rectum and internal anal sphincter is not absolutely necessary for continence [7]. Abdominoperineal resection (APR) with permanent colostomy and sphinctersparing procedures (SSP) are the 2 primary surgical options for rectal cancer. Nevertheless, APR has profound drawbacks, including loss of anorectal function with permanent colostomy and a high incidence of sexual and genitourinary dysfunction. The risk of dying was increased by $30 \%$ among patients with low rectal cancer who underwent APR compared with those undergoing anterior resection. The technical limit is nonanatomical perineal dissection, managed through the ischiorectal fat and the pelvic floor muscles without anatomical landmarks [8]. To overcome these limitations, a number of surgical procedures have been developed, ranging from simple excision to complex resections with reconstruction [6]. Preoperative chemoradiation therapy is widely used to treat locally advanced rectal cancer to increase resectability, and to enhance sphincter preservation, local control, and possibly survival rates. Surgery was performed 6 to 8 weeks after radiotherapy. The study sought to assess the functional outcomes of SSP with TME for anorectal adenocarcinoma using Kirwan grading as a subjective method and the per anal examination scoring system (PASS) as a new objective method, in addition to identifying predictors of poor continence outcomes.

\section{METHODS}

The study protocol was approved by the ethics committee of Mansoura Faculty of Medicine and the Board of Surgery Department of Mansoura University Hospitals. Between December 2012 and November 2017, 93 patients presented with very low rectal cancer were included in the study. Twenty-four patients were excluded due to incontinence, invasion of the external anal sphincter, preoperative incontinence, and loss to follow-up. Patients with anorectal carcinoma were operated after referral by the gastroenterology unit in oncology Center of Mansoura University, Egypt and in Paride Stefanini, Policlinico Umberto Primo hospital, SAPIENZA University of Rome, Italy. After informed consent was obtained from each patient, a complete history, including previous obstetric trauma and anal surgery, was taken. For each patient, general, abdominal, and digital examinations were conducted to exclude presence of a clinically evident metastasis and to assess anal squeeze tone. Routine investigations for anesthetic fitness and tumor markers (carcinoembryonic antigen) were performed. Radiological investigations including pelvis magnetic resonance imaging (MRI) and/or endorectal ultrasound (EUS), abdomen and chest computed tomography scan, and colonos- copy with biopsy were done. Re-evaluation occurred after neoadjuvant chemo-radiotherapy by MRI and EUS. Inclusion criteria included a very low rectal cancer less than $5 \mathrm{~cm}$ from the anal verge or less than $3 \mathrm{~cm}$ from the dentate line with normally continent and tumor-free external anal sphincter. Exclusion criteria were $\mathrm{T} 4$ disease, metastatic tumors, and fecal incontinence (Fig. 1). Stage II/III cases were referred to the clinical oncology and nuclear medicine department of their respective center before surgery. Only 70 eligible patients with anorectal carcinoma were included in this multicentric, phase II, single-group, and open-label study. Excluding one postoperative mortality, early and late functional outcomes were assessed in 69 patients. For stratification of results, a fellow surgeon joined the surgery team in both centers prior to participating in the study. Additionally, surgeons were provided with video recordings of the standardized sphincterpreserving procedures. Incontinence was scored using Kirwan grading score: (1) no incontinence, (2) incontinence to flatus, (3) incontinence to fluids, and (4) incontinence to solid stool. Data were collected prospectively from the time of diagnosis into a custom-written computerized database.

\section{Surgical procedure}

SSP with TME was performed through combined abdominal and transanal approaches. In cases of ISR with TME, the abdominal step was first initiated, followed by transanal dissection and anastomosis. In cases of narrow pelvis or where technical difficulty was expected, the transanal step was initiated first in the inter-

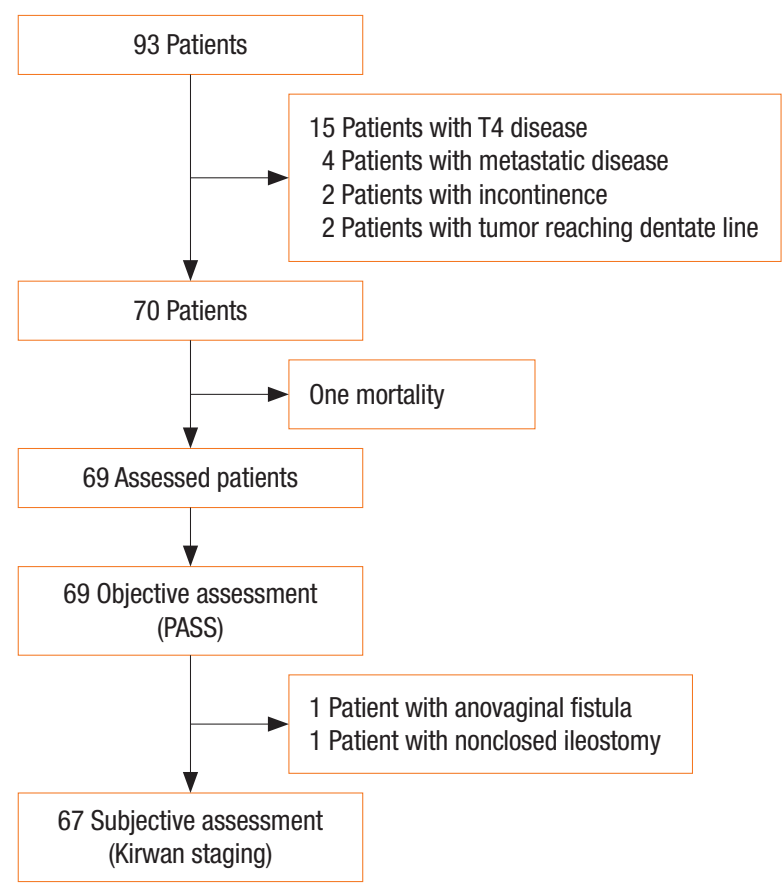

Fig. 1. Flow chart of the studied patients. PASS, per anal scoring system. 
sphincteric plane by transanal endoscopic microsurgery followed by the abdominal step.

The procedure was initiated by incising the peritoneum immediately medial to the inferior mesenteric vessels. The inferior mesenteric vessels were highly ligated. After full mobilization of the left colon and splenic flexure, the plane for TME was initiated superficial to the hypogastric fascia with preservation of the hypogastric plexus and nerves. The rectosacral ligament was opened to enter into the supralevator plane, the sheet of the pelvic floor (levator ani) was incised distally. A circular incision of the anal canal was performed $1 \mathrm{~cm}$ below the tumor (Fig. 2). The rectum was then closed by purse string sutures. The dissection between the internal and the external sphincters was performed. The dissection continued along the levator ani. Transanal division of the superior sheath of the pelvic floor then of the presacral Waldeyer's fascia enabled access for abdominal dissection (Fig. 3). Coloanal anastomosis was done in 2 layers.

\section{Statistical analyses}

Data were analyzed using IBM SPSS Statistics ver. 22.0 (IBM Co., Armonk, NY, USA). Qualitative data were presented as number and percent and compared using chi-square tests. Quantitative data were presented as mean \pm standard deviation and compared by Student t-tests.

\section{RESULTS}

The baseline characteristics of the patients, including the stage and the operative details, are shown in Table 1 . Seventy patients with low rectal cancer underwent SSP with TME. Forty-four patients (62.9\%) underwent partial internal anal sphincter resection

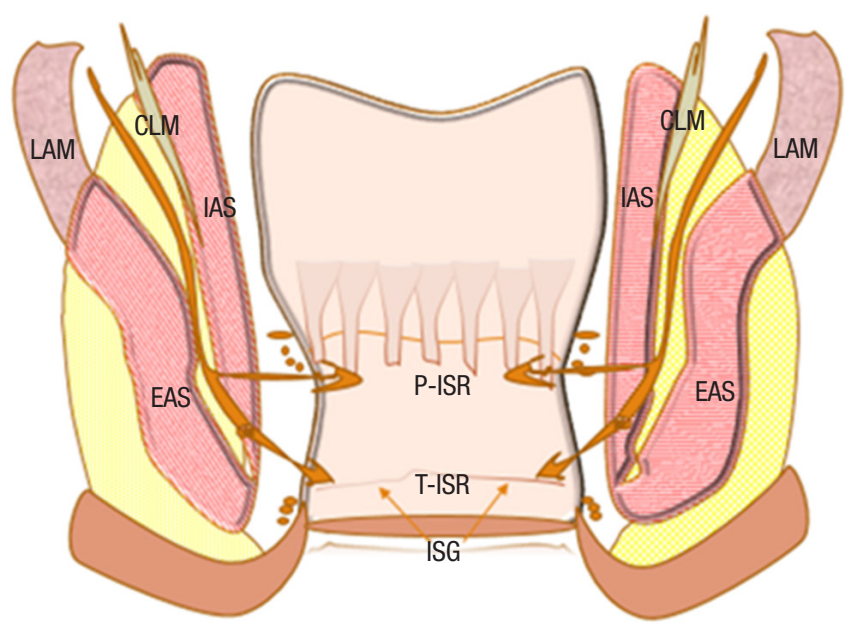

Fig. 2. The plane for partial and total intersphincteric resection in SSP for anorectal adenocarcinoma. EAS, external anal sphincter; IAS, internal anal sphincter; LAM, levator ani muscles; CLM, conjoined longitudinal muscle; PISR, patial intersphincteric resection; TISR, total intersphincteric resection; ISG, intersphincteric groove. with a preservation of $1-2 \mathrm{~cm}$ of the internal anal sphincter where the distal cut margin is at the dentate line and part of the internal sphincter was preserved, while 26 patients (37.1\%) underwent total internal anal sphincter resection where the transanal resection started at the intersphincteric sulcus with complete resection of the internal sphincter. Transanal approach was used as a first step before the abdominal approach in 20 cases $(28.6 \%)$ in which a narrow pelvis was expected.

The early functional outcomes are shown in Table 2 and in-

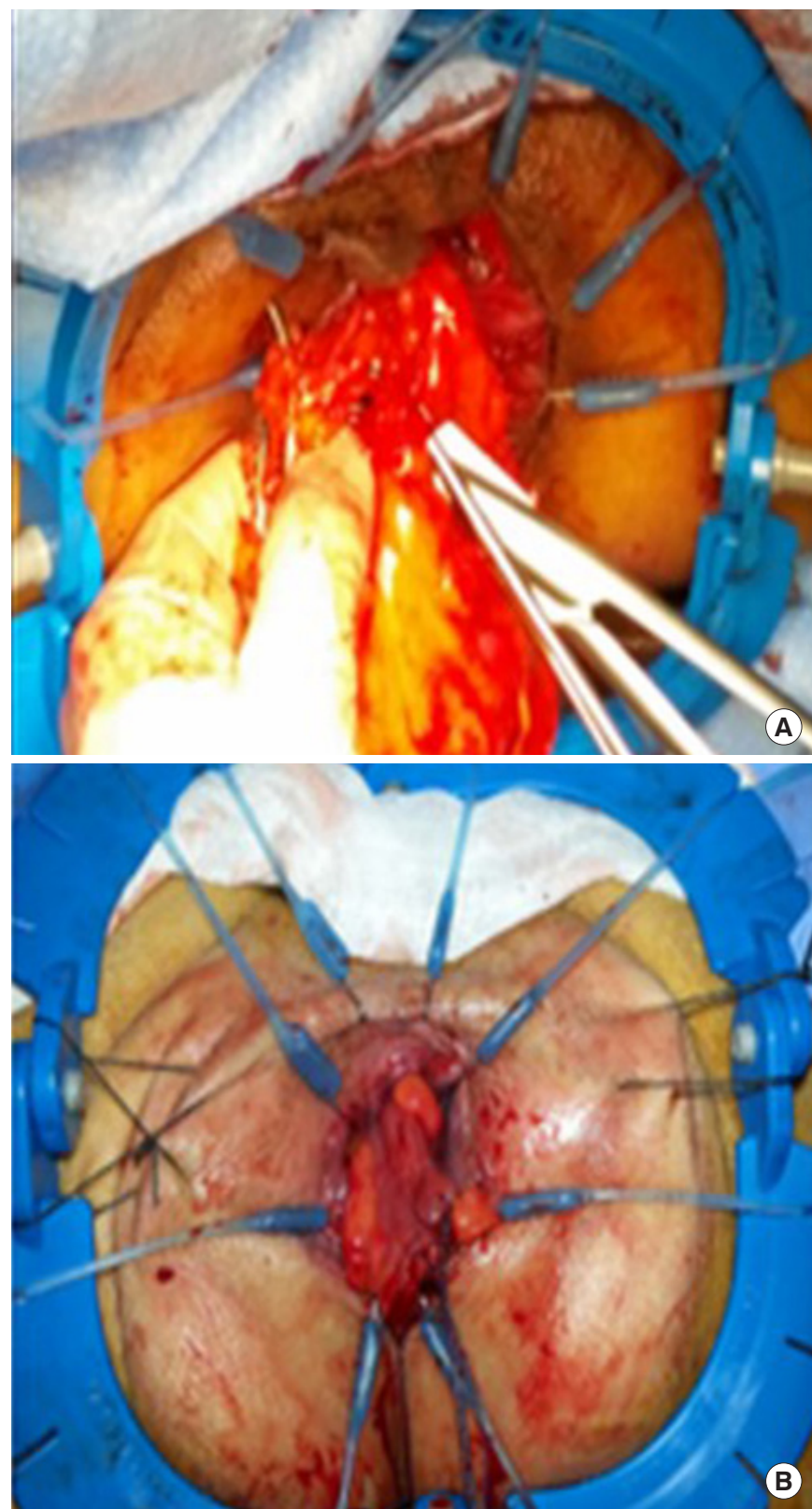

Fig. 3. Transanal division of the resected rectum and part of the anal canal (A) and coloanal anastomosis (B). 
Table 1. Characteristics of surgical patients $(n=70)$

\begin{tabular}{|c|c|}
\hline Characteristic & Value \\
\hline Age (yr) & $58.33 \pm 12.40(28-82)$ \\
\hline \multicolumn{2}{|l|}{ Sex } \\
\hline Male & $45(64.29)$ \\
\hline Female & $25(35.71)$ \\
\hline Body mass index $\left(\mathrm{kg} / \mathrm{m}^{2}\right)$ & $25.86 \pm 3.73(17.35-35)$ \\
\hline Smoking & $22(31.4)$ \\
\hline Diabetes mellitus & $12(17.1)$ \\
\hline Tumor size (mm) & $37.90 \pm 15.02(10-100)$ \\
\hline Tumor distance from the anal verge (mm) & $35.00 \pm 8.31(20-50)$ \\
\hline Tumor distance from the dentate line (mm) & $17(10-20)$ \\
\hline \multicolumn{2}{|l|}{ Presentation } \\
\hline Polypoid & $23(32.9)$ \\
\hline Ulcer & $25(35.7)$ \\
\hline Deeply infiltrating & $22(31.4)$ \\
\hline CEA level (normal $<5 \mathrm{ng} / \mathrm{mL}$ ) & $3.75(2-15)$ \\
\hline$<5 \mathrm{ng} / \mathrm{mL}$ & $42(60)$ \\
\hline$>5 \mathrm{ng} / \mathrm{mL}$ & $28(40)$ \\
\hline \multicolumn{2}{|l|}{ Staging groups } \\
\hline Stage 1 & 6 \\
\hline Stage 2 & 21 \\
\hline Stage 3 & 43 \\
\hline \multicolumn{2}{|l|}{ Surgical procedure } \\
\hline Partial intersphincteric resection & $44(62.9)$ \\
\hline Total intersphincteric resection & $26(37.1)$ \\
\hline Transanal 1st & $20(28.6)$ \\
\hline Anastomosis distance from the anal verge $(\mathrm{mm})$ & $17.64 \pm 9.39(0-35)$ \\
\hline
\end{tabular}

Values are presented as mean \pm standard deviation (range), number (\%), or median (interquartile range).

CEA, carcinoembryonic antigen.

cluded assessment of the time until resumption of bowel motility, time needed for parenteral narcotic analgesia, visual analogue scale for pain, and length of hospital stay. The bowel motility time was measured as the number of hours required after surgery to notice intestinal sounds.

Continence was assessed using Kirwan grading score and PASS (Table 2). Clinical assessment using Kirwan grading score after 9 months showed that 60 of 67 patients $(89.6 \%)$ had good functional outcomes (grade I-II); 31 of 67 patients (46.3\%) and 29 of 67 patients (43.3\%) were Kirwan grade I and II respectively. After 1 year, the number of cases with Kirwan grade I increased up to 42 of 67 patients (62.7\%). Three cases were not included in the assessment using Kirwan grading score due to early mortality, anovaginal fistula with recurrence, and nonclosed ileostomy due to CRM infiltration with high risk for recurrence.
Table 2. Functional outcomes after sphincter-sparing procedures with TME $(\mathrm{n}=67)$

\begin{tabular}{|c|c|}
\hline Functional outcome & Value \\
\hline Bowel motility time (hr) & $50 \pm 19(24-96)$ \\
\hline Parenteral analgesia (hr) & $54.0 \pm 18.8(24-96)$ \\
\hline \multicolumn{2}{|l|}{ VAS } \\
\hline VAS 20 & 39 \\
\hline VAS 40 & 31 \\
\hline Mean score & $28.8 \pm 10.0$ \\
\hline Hospital stay (day) & $15.40 \pm 10.25(5-45)$ \\
\hline Prolonged ileus & $1(1.4)$ \\
\hline Fecal continence & 60/67 (89.6) \\
\hline Fecal incontinence & $7 / 67(10.4)$ \\
\hline Urinary dysfunction & $1(1.4)$ \\
\hline Kirwan grade (9 months) & 67 \\
\hline I, good & $31(46.3)$ \\
\hline II, good & $29(43.3)$ \\
\hline III, poor & $5(7.5)$ \\
\hline IV, poor & $2(2.9)$ \\
\hline Kirwan grade (12 months) & 67 \\
\hline I, good & $42(62.7)$ \\
\hline II, good & $18(26.9)$ \\
\hline III, poor & $5(7.5)$ \\
\hline IV, poor & $2(2.9)$ \\
\hline PASS $^{a}$ & $2.64 \pm 0.891$ \\
\hline Grade 0 & $6(8.7)$ \\
\hline Grade 1 & $18(26.1)$ \\
\hline Grade 2 & $40(58.0)$ \\
\hline Grade 3 & $3(4.3)$ \\
\hline Grade 4 & $2(2.9)$ \\
\hline Total & 69 \\
\hline Ileostomy & $61(87.1)$ \\
\hline Permanent diversion & $4(5.7)$ \\
\hline Atonic sphincter & $2(2.9)$ \\
\hline Local recurrence & $2(2.9)$ \\
\hline
\end{tabular}

Values are presented as mean \pm standard deviation (range) or number (\%).

TME, total mesorectal excision; VAS, visual analogue scale; PASS, per anal scoring system.

aPASS: grade 1, extremely hypotonic sphincter; grade 2, slightly hypotonic sphincter; grade 3, normal tone; grade 4, slightly stenotic anal canal; grade 5, occluded anal canal.

Using PASS, 69 cases were examined after 1 year and the findings were as follows: extremely hypotonic (PASS 0 ) 8.7\% (6 cases), slightly hypotonic (PASS 1) 26.1\% (18 cases), normal tone (PASS 2) $58 \%$ (40 cases), slightly tight (PASS 3 ) 3 cases (4.3\%), and ex- 
Table 3. Predictors of poor continence outcomes after ISR and TME for very low rectal carcinoma

\begin{tabular}{|c|c|c|c|c|}
\hline Variable & $\begin{array}{l}\text { Anal stenosis } \\
\text { (PASS 4) }\end{array}$ & $\begin{array}{l}\text { Marked hypotonicity } \\
\text { (PASS 0) }\end{array}$ & Ileostomy nonclosure & $\begin{array}{c}\text { Postoperative permanent } \\
\text { diversion }\end{array}$ \\
\hline Age $>60 \mathrm{yr}$ & 0.062 & 0.074 & 0.595 & 0.121 \\
\hline Male sex & 0.001 & 0.092 & 0.042 & 0.222 \\
\hline Smoking & 0.096 & 0.056 & 0.081 & 0.243 \\
\hline Diabetes mellitus & 0.061 & 0.134 & 0.021 & 0.564 \\
\hline Tumor location $<3 \mathrm{~cm}$ from the anal verge & $<0.001$ & 0.001 & $<0.001$ & 0.082 \\
\hline Tumor T stage & 0.056 & 0.225 & $<0.001$ & 0.326 \\
\hline Tumor N stage & 0.091 & 0.094 & 0.122 & 0.085 \\
\hline Neoadjuvant therapy & 0.342 & 0.085 & 0.223 & 0.151 \\
\hline Total ISR & 0.041 & 0.042 & 0.004 & 0.141 \\
\hline Laparoscopic versus open ISR & 0.321 & 0.534 & 0.330 & 0.071 \\
\hline Length of the specimen & 0.723 & 0.612 & 0.969 & 0.128 \\
\hline Colonic necrosis & $<0.001$ & 0.631 & $<0.001$ & 0.09 \\
\hline
\end{tabular}

ISR, intersphincteric resection; TME, total mesorectal excision; PASS, per anal scoring system.

tremely tight (PASS 4) 2.9\% (2 cases). Extremely tight anal sphincter (PASS 0$)$ was significantly related to male sex $(\mathrm{P}=$ $0.001)$, tumor location less than $3 \mathrm{~cm}$ from the anal verge $(\mathrm{P} \leq$ $0.001)$, and colonic necrosis at the anastomotic site $(\mathrm{P} \leq 0.001)$. On multivariate regression analysis, male sex $(\mathrm{P}=0.02)$ and colonic necrosis $(\mathrm{P} \leq 0.01)$ were the only dependent factors for occurrence of anal stenosis. Extremely hypotonic sphincter was related to tumor location less than $3 \mathrm{~cm}$ from the anal verge $(\mathrm{P}=0.001)$ and total resection of the internal anal sphincter $(\mathrm{P}=0.042)$. Multivariate regression analyses for predictors of extremely hypotonic sphincter were closely related to total resection of the internal anal sphincter $(\mathrm{P} \leq 0.001)$.

Temporary diversion was done in 61 patients (87.1\%). Permanent diversion was required in 4 cases, 2 for local recurrence and 2 due to atonic sphincter. Urinary dysfunction occurred in 1 case (1.4\%).

The overall incidence of reoperation in the study group after SSP and TME was 12 (17.1\%) in 11 cases (15.7\%) as follows: debridement and reanastomosis for 2 cases of colonic necrosis, temporary ileostomy and anastomotic revision for 2 cases, permanent diversion for 1 anovaginal fistula with local recurrence, 1 re-exploration for pelvic hematoma, ultrasound gluteal guided drainage for 2 cases for pelvic abscess, 1 diamond flap for anal stenosis, and 3 permanent diversions ( 2 atonic anal sphincter and 1 local recurrence).

\section{DISCUSSION}

Despite progress in neoadjuvant therapy, radical resection of rectal carcinoma is the only hope for permanent cure of rectal cancer [6]. Continence-preserving radical resection and optimal local tumor control are currently achievable goals in the treatment of ul- tralow rectal carcinoma. Successful excision of a low rectal tumor while preserving the anal sphincter requires knowledge of the pattern of tumor spread and an understanding of the physiology of the sphincter mechanism. The move towards sphincter-preserving surgeries began with early anorectal physiology work demonstrating that the distal $1-2 \mathrm{~cm}$ of the rectum and internal anal sphincter are not absolutely necessary for continence [7]. The goal of SSP is to divide the rectum transanally and to remove a part of or the whole internal anal sphincter, in order to obtain adequate distal margin and preserve the natural function of defecation. This technique modified the concept of sphincter preservation, because it theoretically allows surgeons to avoid APR in most rectal cancers due to the possibility of obtaining safe distal margins in all cases [8].

The technique for ISR was first described by Schiessel et al. [6], who undertook the procedure to enable restorative resection and avoidance of a permanent stoma. In our study, straight colo-anal anastomoses were performed, which are the same in all recent ISR studies [9-12]. In our study, a diverting temporary ileostomy was performed in 61 patients (87\%), which is created with usual closure of the ileostomy either 1 month postoperative or after completion of adjuvant therapy. In other studies, the rate of diverting ileostomy in ISR ranged between $77 \%$ and $90 \%[10,12]$. A temporary stoma is typically used in an attempt to decrease the incidence of perianastomotic infections and the occurrence of muscular fibrosis of the external anal sphincter. In our study, the mean distance of the anastomosis from the anal verge was $17.64 \pm 9.39 \mathrm{~mm}$. Additionally, clinical assessment using Kirwan grading scores after 9 months showed that 60 patients (87.6\%) had good functional outcomes (grade I and II); 31 patients (46.3\%) and 29 patients (43.3\%) were Kirwan grade I and II respectively. After 1 year, the number of cases with Kirwan grade I 
increased up to 42 patients (62.7\%) and Kirwan grade II decreased to 18 cases $(26.9 \%)$ with a total good continence function of $(89.6 \%)$ after 1 year. In a systematic review, Akagi et al. [13] described Kirwan grades after ISR as follows: grade I (13.9\%$84.6 \%)$, grade II $(7.7 \%-36.6 \%)$, grade III $(3.8 \%-38.6 \%)$, and grade IV (0\%-27\%).

Assessment of anal continence has been considered a crucial point for assessing anal dysfunction. To the best of our knowledge, no postoperative scoring system has been used to assess anal function after very low rectal cancer resection. The first trials to assess anal function developed grading scores depending on the amount and frequency of soiling and use of pads $[14,15]$. More recently, the digital rectal examination scoring system (DRESS) with 6 grades of continence was used previously as a good objective scoring system for assessing anal sphincter tone [16]. DRESS is not a reasonable scoring system for assessing postoperative anal function. Postoperative anal canal function depends on both the tone of the sphincter and the postoperative fibrosis evoked by the neoadjuvant radiotherapy and the postoperative granulation tissue. DRESS has 2 main disadvantages; first, there is no clinical difference between atonic (category 0 ) and extremely hypotonic sphincter (category 1) in regard to presentation or management. Secondly, DRESS does not take into consideration the presence of organic anal stenosis, which is a real indicator of poor anal function. The PASS is a modification of DRESS that includes 5 grades of postoperative anal function: grade 1 (extremely hypotonic sphincter), grade 2 (slightly hypotonic sphincter), grade 3 (normal tone), grade 4 (slightly stenotic anal canal), and grade 5 (occluded anal canal).

Using PASS, anal canal function was examined in 69 cases after 1 year and found to be as follows: extremely hypotonic (6\%), slightly hypotonic (18\%), normal tone (58\%), slightly stenotic (4.3\%), and extremely tight (3\%). Schiessel et al. [6] reported perfect continence in almost $80 \%$ of patients, as indicated by normal squeeze pressure on digital rectal examination.

Continence deficits occurring after rectal resection have multifactor origins. In our study, markedly hypotonic anal sphincter (PASS 0), presence of anal stenosis (PASS 4), nonclosure of ileostomy, and postoperative permanent diversion were considered indicators of poor functional outcome (Table 3). In our study, poor continence outcomes were found to be significantly related to the following factors: male sex, tumor location less than $3 \mathrm{~cm}$ from the anal verge, tumor $\mathrm{T}$ stage, total resection of the internal anal sphincter, and occurrence of postoperative colonic necrosis, which is strictly related to anal stenosis. Anal stenosis occurred in 4 cases $(5.7 \%)$ and was greatly associated with conservatively treated colonic necrosis; 3 cases were slightly stenotic and were treated conservatively by dilation and 1 case was occluded and treated using diamond island flap. Lim et al. [9] reported 6.3\% incidence of postoperative stenosis, which were treated conservatively using Higar dilatation. The management of patients with bad functional outcomes is difficult. As noted above, bowel func- tion may improve over time, but this must be assisted by a low fiber diet and drug therapy (loperamide or codeine). If this fails, formation of an end colostomy may be necessary [17]. In our study, urinary dysfunction occurred in 1 case (1.4\%). Urinary dysfunction was reported to occur in cases of injury to the sympathetic pelvic nerves [18]. Permanent diversion was required in 4 cases (5.7\%), 2 for local recurrence and 2 due to the presence of atonic sphincter. Laurent et al. [11] reported a similar result, with a 5.4\% rate of permanent diversion. Köhler et al. [19] reported a higher rate of permanent diversion, $12.9 \%$ (4 cases), which can be explained by the small number of cases (31) in the included study and the longer term of follow-up (6.8 years).

PASS is a new quantifiable clinical scoring system for the postoperative assessment of anal function and has the advantage of being simple, objective, rapid, and reliable for expressing the degree of anal incontinence in an outpatient setting, especially where the manometric studies are not available. PASS should be incorporated with Kirwan scoring for complete reflection of postoperative anal function.

In conclusion, SSP with TME are feasible for anorectal adenocarcinoma and can provide reasonable anal function. PASS is a new scoring system that can adequately express postoperative anal function.

\section{CONFLICT OF INTEREST}

No potential conflict of interest relevant to this article was reported.

\section{REFERENCES}

1. Heald RJ, Husband EM, Ryall RD. The mesorectum in rectal cancer surgery--the clue to pelvic recurrence? Br J Surg 1982;69:613-6.

2. Bai X, Li S, Yu B, Su H, Jin W, Chen G, et al. Sphincter-preserving surgery after preoperative radiochemotherapy for T3 low rectal cancers. Oncol Lett 2012;3:1336-40.

3. Karanjia ND, Schache DJ, North WR, Heald RJ. 'Close shave' in anterior resection. Br J Surg 1990;77:510-2.

4. Han F, Li H, Zheng D, Gao H, Zhang Z. A new sphincter-preserving operation for low rectal cancer: ultralow anterior resection and colorectal/coloanal anastomosis by supporting bundling-up method. Int J Colorectal Dis 2010;25:873-80.

5. Wibe A, Syse A, Andersen E, Tretli S, Myrvold HE, Søreide O, et al. Oncological outcomes after total mesorectal excision for cure for cancer of the lower rectum: anterior vs. abdominoperineal resection. Dis Colon Rectum 2004;47:48-58.

6. Schiessel R, Karner-Hanusch J, Herbst F, Teleky B, Wunderlich M. Intersphincteric resection for low rectal tumours. Br J Surg 1994; 81:1376-8.

7. Kapiteijn E, Marijnen CA, Nagtegaal ID, Putter H, Steup WH, Wiggers T, et al. Preoperative radiotherapy combined with total mesorectal excision for resectable rectal cancer. N Engl J Med 


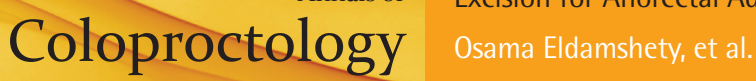

\section{1;345:638-46.}

8. Rullier E, Laurent C, Bretagnol F, Rullier A, Vendrely V, Zerbib F. Sphincter-saving resection for all rectal carcinomas: the end of the 2-cm distal rule. Ann Surg 2005;241:465-9.

9. Lim SW, Huh JW, Kim YJ, Kim HR. Laparoscopic intersphincteric resection for low rectal cancer. World J Surg 2011;35:2811-7.

10. Fujii S, Yamamoto S, Ito M, Yamaguchi S, Sakamoto K, et al. Short-term outcomes of laparoscopic intersphincteric resection from a phase II trial to evaluate laparoscopic surgery for stage 0/I rectal cancer: Japan Society of Laparoscopic Colorectal Surgery Lap RC. Surg Endosc 2012;26:3067-76.

11. Laurent C, Paumet T, Leblanc F, Denost Q, Rullier E. Intersphincteric resection for low rectal cancer: laparoscopic vs open surgery approach. Colorectal Dis 2012;14:35-41.

12. Chi P, Huang SH, Lin HM, Lu XR, Huang Y, Jiang WZ, et al. Laparoscopic transabdominal approach partial intersphincteric resection for low rectal cancer: surgical feasibility and intermediateterm outcome. Ann Surg Oncol 2015;22:944-51.

13. Akagi Y, Kinugasa T, Shirouzu K. Intersphincteric resection for very low rectal cancer: a systematic review. Surg Today 2013;43:
838-47.

14. Miller R, Bartolo DC, Locke-Edmunds JC, Mortensen NJ. Prospective study of conservative and operative treatment for faecal incontinence. Br J Surg 1988;75:101-5.

15. Pescatori M, Anastasio G, Bottini C, Mentasti A. New grading and scoring for anal incontinence. evaluation of 335 patients. Dis Colon Rectum 1992;35:482-7.

16. Orkin BA, Sinykin SB, Lloyd PC. The digital rectal examination scoring system (DRESS). Dis Colon Rectum 2010;53:1656-60.

17. Chatwin NA, Ribordy M, Givel JC. Clinical outcomes and quality of life after low anterior resection for rectal cancer. Eur J Surg 2002;168:297-301.

18. Lindsey I, Guy RJ, Warren BF, Mortensen NJ. Anatomy of Denonvilliers' fascia and pelvic nerves, impotence, and implications for the colorectal surgeon. Br J Surg 2000;87:1288-99.

19. Köhler A, Athanasiadis S, Ommer A, Psarakis E. Long-term results of low anterior resection with intersphincteric anastomosis in carcinoma of the lower one-third of the rectum: analysis of 31 patients. Dis Colon Rectum 2000;43:843-50. 